\title{
PHYSICAL AND CHEMICAL QUALITY CHARACTERISTICS OF CORN TORTILLAS WITH SUBSTITUTE PURPLE SWEET POTATO FLOUR
}

\author{
Nurfitrianti Bolutioo $^{1)}$, Adnan Engelen ${ }^{2)}$, Nursia Lateka ${ }^{3)}$ \\ 1,2,3 Department of Agricultural Product Technology, Polytechnic of Gorontalo, \\ Jl Muchlis Rahim, Panggulo Barat, Gorontalo, 96551 - Indonesia \\ *Corresponding E-mail : adnanengelan@poligon.ac.id \\ E-mail : bulotionur@gmail.com \\ From Indonesia
}

\begin{abstract}
This study aimed to test the physical and chemical quality characteristics of corn tortillas with substitute purple sweet potato flour. This study used a completely randomized design (CRD) and LSD test if there was a significant effect. The tests carried out included organoleptic tests, air content analysis, ash content analysis, color analysis and texture analysis. The results showed that the best formulation of tortillas chips was a P4 treatment with the addition of $75 \%$ purple sweet potato flour: $25 \%$ corn, with a texture value of 4.267 , taste 4.75 and aroma 4.56 and for the best color treatment found in the addition of $\mathrm{P} 3 \mathrm{had}$ a value of 4.31 . The best treatment in the chemical analysis is the $\mathrm{P} 4$ treatment had a color value of -10.93, moisture content of 8.94 and ash content of 2.57. For texture analysis test the highest treatment was $\mathrm{P} 2$ treatment with the addition of $25 \%$ purple sweet potato flour: $75 \%$ corn with a value of 1139.15 .
\end{abstract}

Keywords : tortillas, corn, purple sweet potato flour

\section{INTRODUCTION}

Corn is an easy-to-grow plant in Gorontalo, so maize production is plentiful, particularly in the province. Pulut maize is a form of maize that is widely grown in Gorontalo. Pulut corn has a delicious flavor and is more savory, fluffier, and smoother than regular corn. Corn starch (maizena), corn oil, corn rice, and snacks are examples of corn-based foods. Tortillas are one of the corn snack products.

Tortillas are made from homini corn as the main ingredient. Crop that has undergone a stabilization phase is known as homini corn. Nikstamalization is the process of cooking corn grains in a lime solution $(\mathrm{Ca}(\mathrm{OH}) 2)$, then immersing them in boiling water for several hours, washing them, and milling them into a doughy mass (Mendez et al 2006). To make tortillas, you'll need to go through three steps: making nikstamal, making dough, and baking the dough into tortillas. Corn tortillas have a distinctive yellow hue, are crunchy and small, and are easily crushed.

The physicochemical properties of the tortilla produced are determined by the properties of corn as well as the form and proportion of flour used as a binding agent in the manufacturing process. The choice of corn kernels and process control are the deciding factors in obtaining the perfect tortilla. In the form of rice, flour is used as a binder in tortillas. About the fact that Indonesia does not produce flour. As a result, finding a flour substitute made from local ingredients, such as tubers in the form of purple sweet potatoes, is important to minimize reliance on wheat flour.
Purple sweet potatoes also have the benefit of being rich in antioxidants, which help to neutralize free radicals that induce premature aging. Power, vitamin $C$, and vitamin $B 6$, all of which are essential for immunity, are also present in purple sweet potatoes. Purple sweet potato plays an important role in food diversification and can be transformed into a number of products, and can help to promote agroindustrial production and food safety (Zuraida and Supriyati, 2011). As a result, purple sweet potato flour was made.

The usage of purple sweet potato flour as a wheat flour replacement in tortillas is projected to limit the use of wheat flour, thus reducing wheat flour imports. Apart from sweet potatoes, other flours have been used to make tortillas, such as Dolongseda et al. (2010)'s research, which used jackfruit seed flour as a wheat flour replacement. As a result, the variety of corn used and the binding agent used have an effect on the consistency of corn tortillas. As a result, further research is required to decide the right combination of corn concentration and binder (purple sweet potato flour) so that the tortillas' consistency can be recognized by the population.

\section{RESEARCH METHODS}

\subsection{Place and Time of Research}

This study was carried out in June 2020 at Gorontalo of Polytechnic, Laboratory of Agricultural Product Technology. 


\subsection{Material And Methods For Analysis}

The main ingredient used was corn and purple sweet potato that originates from the Gorontalo City central market. Other ingredients used to make dry noodles included salt, garlic powder, water, oil,lime and pepper. A drying oven, grinder, plastic container, beaker,measuring cup, strainer / sieve, timer, stove, analytical scales, porcelain dishes, glass texture analyser, and colorimeter equipment were the instruments used for this study. The drying oven was square, $100 \mathrm{~cm} \times 100$ $\mathrm{cm}$ tall. Treatment control (100 percent of corn : 0 percent of purple sweet potato flour), Purple sweet potato flour : corn (25 percent : 75 percent), Purple sweet potato flour : corn (50 percent : 50 percent), and Purple sweet potato flour : corn (75 percent : 25 percent). The results of the data analysis were then carried out by the variance test.

\subsection{Production}

The procedure for making tortilla chips refers to the research that has been conducted (Adinda, 2017).

1. To make tortillas, the corn kernels are first separated from the cobs.

2. Furthermore, the corn ( 75 grams) is soaked for \pm 24 hours by adding lime ( $1 / 2 \mathrm{tsp})$ and water then boiled then washed and drained.

3. It is then milled, and the ingredients are combined (according to the treatment) into a smooth dough.

4. Next, the dough is flattened with a flattening tool and then cut into rectangles.

5. The pieces of dough in the form of sheets are then dried in an oven for \pm 20 minutes at a temperature of $120^{\circ} \mathrm{C}$.

6. The dried tortillas are then fried.

\subsection{Analysis Procedure}

\subsubsection{Analysis of The Water Content (Codex} Standard 2006)

The plates were heated for 15 minutes at 105 ${ }^{\circ} \mathrm{C}$, during which the plates were refrigerated for 15 minutes in a desiccator.

The plate containing the sample shall be set in an oven for 4 hours at $105^{\circ} \mathrm{C}$. After that, the plates were refrigerated for 15 minutes in a desiccator and then weighed again. The water content of tortilla chips is calculated using the formula below :

$$
\text { Moisture content }(\% \mathrm{bb})=\frac{(x-y)}{(x-a)} \times 100
$$

Note.

$\mathrm{x}=$ weight of plates and samples before drying $(\mathrm{g})$

$\mathrm{y}=$ plate and sample weight after drying $(\mathrm{g})$

$\mathrm{a}=$ weight of empty cup $(\mathrm{g})$

\subsubsection{Analyzing of The Ash Content (Andarwulan et al, 2011)}

The empty slabs are measured like a gram. 5 grams of the test material are then placed into a cup, weighed and registered as weight $b$ grams. Ashes are performed in 2 phases, namely heating at $300{ }^{\circ} \mathrm{C}$ to preserve the volatile and fat content before the acid content is lost.. Heating up until the acid runs out more, steadily heating up to $600^{\circ} \mathrm{C}$ at a rate such that abrupt temperature changes do not cause the cup to burst. Can measure the ash content in the sample using the formula:

$$
\% \text { Ash } \frac{\mathrm{W} 2-\mathrm{W} 1}{W 1-W 0} X 100
$$

Note:

$\mathrm{W} 0=$ Weight of empty cup $(\mathrm{g})$

$\mathrm{W} 1=$ Weight of plate + sample before ashing $(\mathrm{g})$

$\mathrm{W} 2=$ Weight of plate + sample after ashing $(\mathrm{g})$

\subsubsection{Color Analysis (Andarwulan et al, 2011)}

Color measurement using the AMT-507 handheld colorimeter. Measurements generate values of $\mathrm{L}, \mathrm{C}$, and $\mathrm{H}, \mathrm{L}$ denote parameters of brightness (achromatic colour, 0: black to 100: white), $\mathrm{C}$ denotes the level of color based on its sharpness, which determines the color of an object that tends to be pure or that tends to be dirty. (gray). Saturation follows a percentage ranging from 0 percent to 100 percent as the sharpest colour, Hue is a color attribute dependent on the light reflected by the material, it is seen from its size following levels 0 to 359 in terms of colour. For eg, at level 0 is Red, for Green, 60 is Yellow at 120 levels, while those at 180 are cyan (turquoise). For level 240 is a color Blue, and 300 is a color Magenta.

\subsubsection{Measurement of Texture Profile Analysis (TPA) (AACC 66-50.01.1999)}

Using Texture Analyser (HD-Plus) tool to analyze the texture. The probe used has a diameter of $35 \mathrm{~mm}$. The distance from the probes is $20 \mathrm{~mm}$. The measuring method is for a rehydrated sample with a length exceeding the diameter of the probe to be positioned on the anvil and then pressed by the probe. The effect is a curve that shows the relation between the force of deformation and the time. The hardness value is given by the absolute (+) peak, which is the maximum power, and the absolute-) (peak indicates the stickiness value. The unit for each of these parameters is gram force (gf). The elasticity is obtained from the ratio of unit gram second (gs) between the two compressive areas. 


\section{RESULTS AND DISCUSSION}

\subsection{Organoleptic Test}

\section{1.. Color}

According to Bello et al (2013), Color is one of the important quality characteristics and major factors affecting sensory perception and consumer acceptance of foods. Besides that, there are other considerations like microbiological characteristics , for example. Compared to other factors the color aspect comes first and is very definitive. The results are shown in Figure 1, based on the organoleptic test on color of tortillas chips.

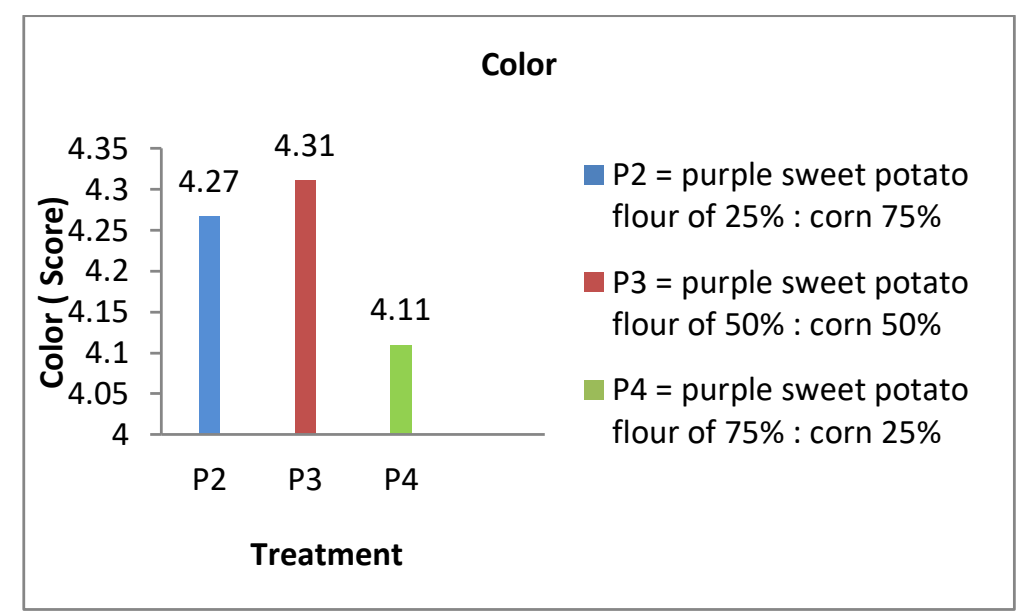

Figure 1. Graph of preferred amount for tortillas chips taste

Figure 1 shows the results of the panelist's assessment of the color of tortilla chips with purple sweet potato flour which had the highest value in P2 treatment with the addition of $50 \%$ corn and $50 \%$ purple sweet potato flour with a value of 4.31 or in the normal / neutral level to slightly like it.

From all treatments panelists preferred the color of purple sweet potato chips in treatment P3 because in this treatment, the contribution of purple sweet potato flour was as much as corn compared to other treatments so that the resulting color in this treatment was not too purple. This is in accordance with the opinion (Winarno, 2004) which states that the determination of the quality of a material generally depends on the color.

\subsubsection{Flavor}

The Flavor is an odor induced by chemical stimulation that reflect information derived from multiple sensory afferents, including gustatory, olfactory, and somatosensory fibers. Although flavor perception therefore arises from the central integration of multiple sensory inputs, it is possible to distinguish the different modalities contributing to flavor, especially when attention is drawn to particular sensory characteristics (Stevenson, 2012). The results are defined in Figure 2 based on the results of the hedonic test on flavor parameters can be seen in the figure below.

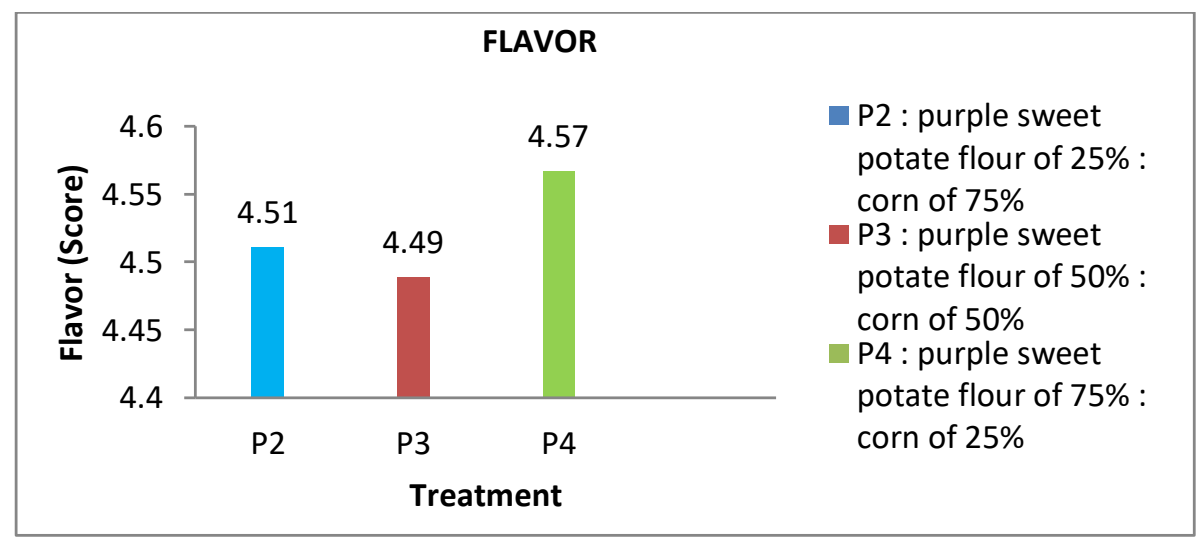

Figure 2. Graph of preferred amount for tortillas chip flavor 
Figure 2 shows the results of the panelists assessment of the aroma of tortilla chips with purple sweet potato flour which was considered the most preferred by the panelists in the $\mathrm{P} 4$ treatment with the addition of $25 \%$ corn and $75 \%$ purple sweet potato flour with a value of 4.566 , while the lowest value was in the P3 treatment with addition of $50 \%$ corn and $50 \%$ purple sweet potato flour with a value of 4.48 , or in the level of preference by the panelists. This is because the contribution of purple sweet potato flour is more in this treatment compared to other treatments. So that it affects the aroma of these tortilla chips. The fragrant and distinctive aroma of sweet potato flour comes from its degraded starch content. This is in accordance with the opinion
(Rodriques et al, 1998) which states that the formation of aroma and flavor is caused by degraded carbohydrate content in sweet potatoes.

\subsubsection{Taste}

The taste buds can discern four main flavours, namely salty, sour, sweet, bitter, and umami according to Melis and Barbarossa (2017). There are several factors influencing the taste, including chemical compounds and their interactions with other elements. The results are defined in Figure 1 based on the organoleptic test for the taste of tortillas chips.

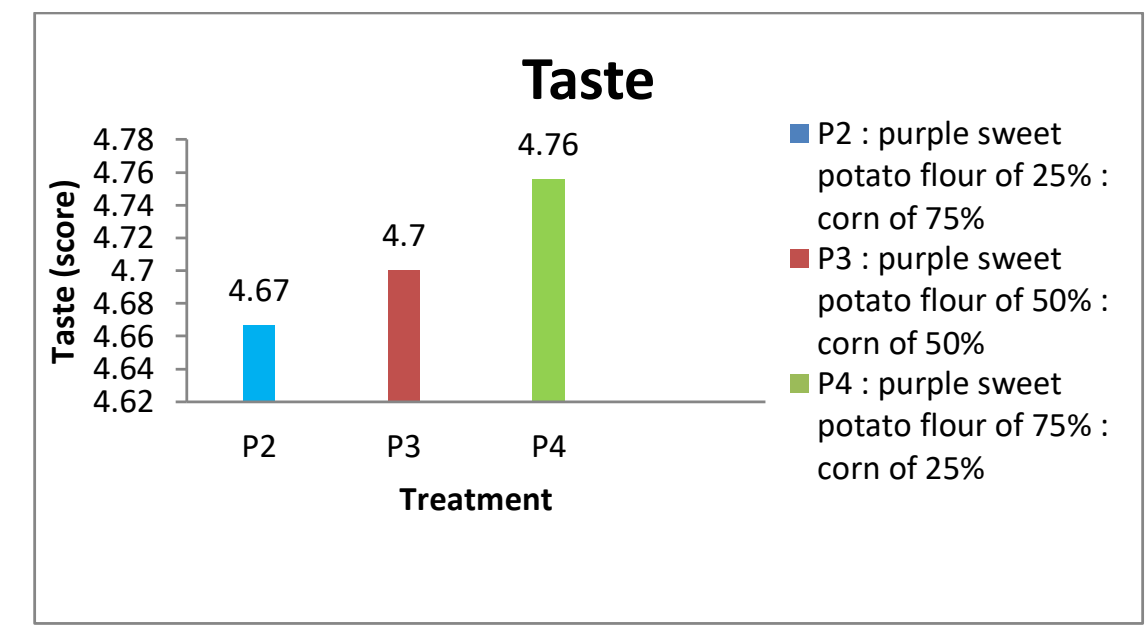

Figure 3. Graph of preferred amount for tortillas chip taste

Figure 3 shows the results of the panelists' assessment of the taste of torila chips with purple sweet potato flour with the highest value in treatment P4 with the addition of $25 \%$ corn and $75 \%$ purple sweet potato flour with an average value of 4.756 and the lowest in treatment P2 with the addition of $75 \%$ corn and $25 \%$ purple sweet potato flour with a value of 4.67 or neutral to like. Panelists liked the tortilla taste somewhat in treatment P4 compared to other treatments. This is estimated because in this treatment the contribution of purple sweet potato flour is greater than that of corn compared to other treatments. So the taste is more dominant in the taste of purple sweet potato.

\subsubsection{Texture}

Based on the organoleptic test on the texture parameters of the purple sweet potato flour tortilla chips, the three treatments can be seen in the following Figure. 


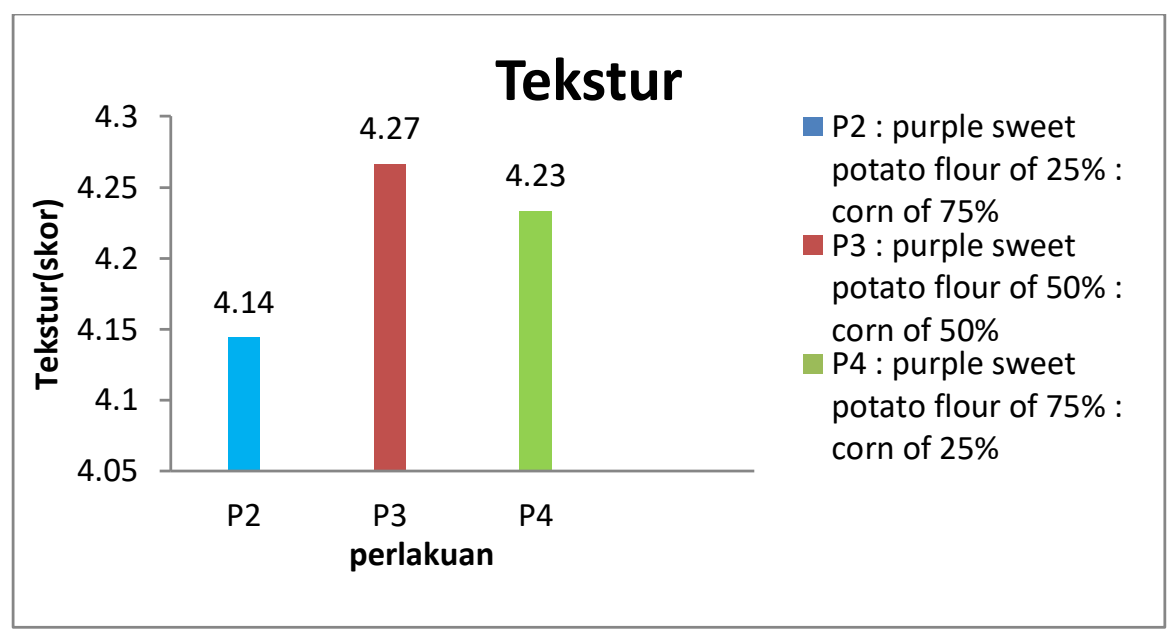

Figure 4. Graph of preferred amount for tortillas chip texture

Figure 4 shows the results of the panelists' assessment of the taste of torila chips with purple sweet potato flour with the highest value in the $\mathrm{P} 3$ treatment with the addition of 50\% corn and 50\% purple sweet potato flour with an average value of 4.267 and the lowest in treatment P2 with the addition of $75 \%$ corn and $25 \%$ purple sweet potato flour with a value of 4.14 or neutral to like.

This is because the P3 treatment in making tortilla chips is crunchier so that it is preferred by the panelists compared to other treatments. This is presumably in the P3 treatment the proportion of purple sweet potato flour and corn is the same as compared to the other treatments because it is known that both ingredients have a high enough amylopectin content so that the resulting texture is more crunchy. This is in accordance with the opinion (Kusmawati, et al., 2000) which states that the texture is acceptable if the material is in a normal state and depends on the specific material.

\subsection{Chemical Properties Analysis}

\subsubsection{Moisture Content}

The results of the analysis of the average moisture content of the purple sweet potato flour tortilla chips from three treatments with three repetitions of the analysis with the average results are presented in Figure 5.

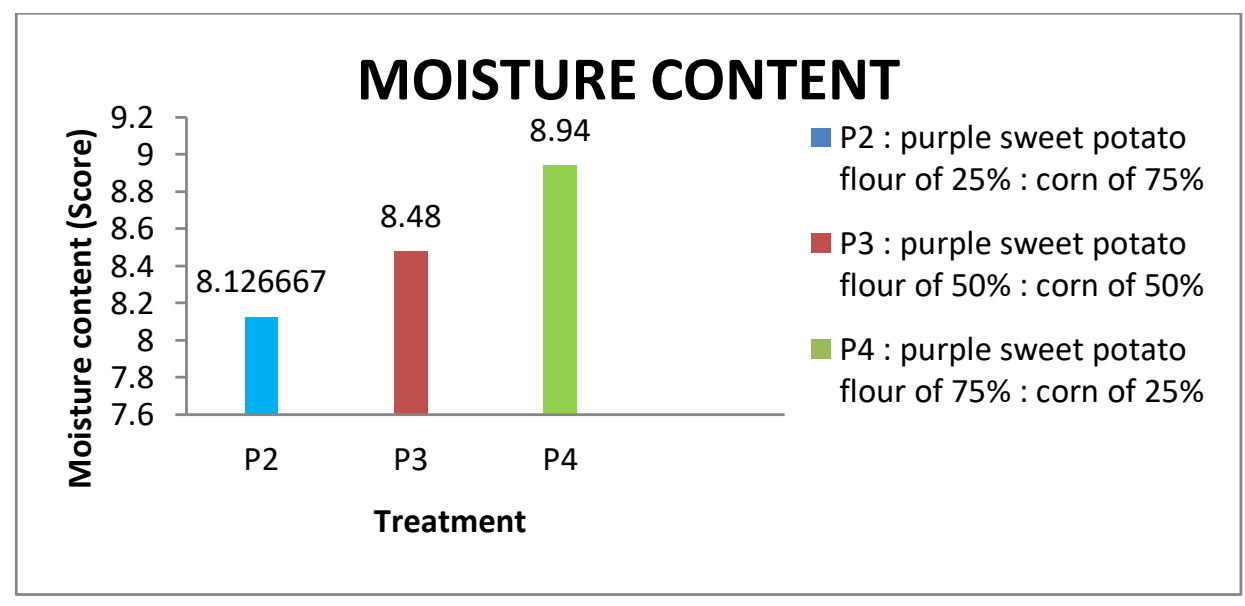

Figure 5. The results of an analysis of the tortillas chips' moisture content

Figure 5 shows the results of the highest water content assessment in treatment $\mathrm{P} 4$ with the addition of $75 \%$ corn and $25 \%$ purple sweet potato flour with an average value of 8.94 , while the lowest water content was in treatment $\mathrm{P} 2$ with the addition of $25 \%$ corn and $75 \%$ purple sweet potato flour with the addition of $25 \%$ corn and $75 \%$ purple sweet potato flour. mean value 8.12 . This shows that the contribution of sweet potato flour has a lot of influence on the water content of tortilla chips. The more the sweet potato flour is added, the water content will also increase. This is presumably 
because the increase in water content is caused by the presence of carbohydrates in purple sweet potato flour which is high enough to play a role in the manufacture of starch, the starch dough formed is able to hold water. According to SNI, the maximum water content for tortilla chips is $4 \%$, the resulting moisture content is higher than the SNI standard. This shows that the water content produced by the purple sweet potato flour tortilla chips does not meet the SNI standard.

Based on the results of the analysis of the variety of water content in tortilla, it was stated that the value of Fcount was 0.32 , this value was smaller than Ftable (0.05), namely 5.14 and Ftable (0.01), namely 10.92 , this variance analysis showed that the difference in treatment the tortilla had no significant effect on the moisture content obtained, so there was no need for further LSD tests. This shows that the water content in each treatment of purple sweet potato flour tortilla chips is quite high so that the level of product damage is also quite high. This is presumably because the lower the water content of a material, the lower the level of damage and the higher the water content of a material, the faster the rate of deterioration of the material itself.

\subsubsection{Ash content}

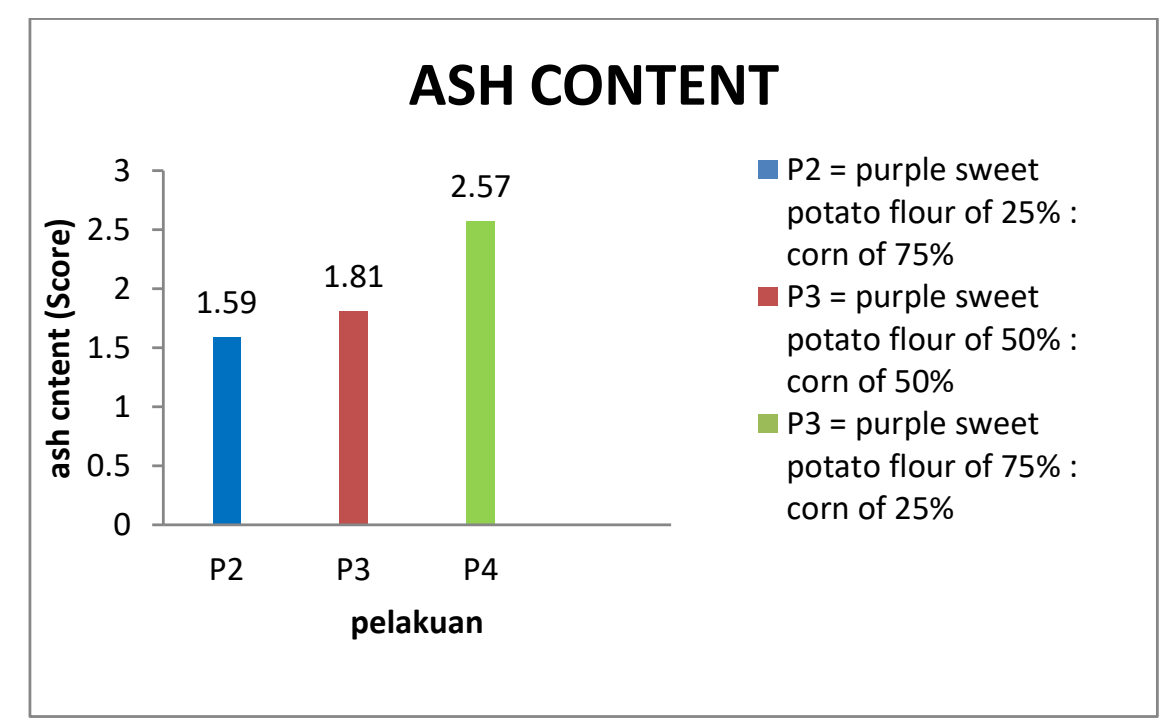

Figure 6. The results of an analysis of the ash content of tortillas chips

Figure 6 shows the results of the highest ash content assessment in $\mathrm{P} 4$ treatment with the addition of $25 \%$ corn and $75 \%$ purple sweet potato flour with an average value of 2.57 while the lowest ash content was in treatment $\mathrm{P} 2$ with the addition of $75 \%$ corn and $25 \%$ purple sweet potato flour. with an average value of 1.59 . This shows the contribution of sweet potato flour which affects the ash content of the tortilla chips a lot. The more purple sweet potato flour was added, the ash content would increase. This is because the mineral content in purple sweet potato flour is higher. This is in accordance with the opinion of Koswara (2013) which states that the most minerals in purple sweet potato are potassium while other types of minerals are sodium, phosphorus, calcium, magnesium and iron. Minerals have an important role in the body because they function as builders and regulators of metabolic processes in the body. The mineral content in food can be estimated as the ash content which is the residual inorganic that remains after the organic materials are burned out. The more mineral content of a material, the higher the ash content, these minerals can be in the form of organic salts (Waryoko, 2007).

\subsubsection{Color}

The results of the color analysis of purple sweet potato flour tortilla chips from three treatments with three analysis replications can be seen in Table 1 and Figure 7 below: 
Table 1

The color analysis of purple sweet potato flour tortilla chips

\begin{tabular}{ccccc}
\hline Treatment & $\Delta \mathbf{L}$ & $\Delta \mathbf{a}$ & $\Delta \mathbf{b}$ & $\Delta \mathbf{E}$ \\
\hline P1 & & STANDAR & & \\
P2 & -1.40 & 6.73 & 4.70 & 15.47 \\
P3 & -4.27 & 11.33 & 28.30 & 30.87 \\
P4 & -10.93 & 13.60 & 29.80 & 34.69 \\
& & & & \\
\hline
\end{tabular}

\begin{tabular}{|c|c|c|c|c|}
\hline \multicolumn{5}{|c|}{ COLOR TEST } \\
\hline $\begin{array}{l}\text { 0ँ } \\
\frac{\dot{0}}{0} \\
\frac{\dot{0}}{0}\end{array}$ & $\begin{array}{r}0 \\
-2 \\
-4 \\
-6 \\
-8 \\
-10 \\
-12\end{array}$ & $\begin{array}{l}P 2 \\
-1.4\end{array}$ & $\begin{array}{l}\text { P3 P4 } \\
-4.27 \\
\\
\text { Treatment }\end{array}$ & $\begin{array}{l}\text { P2 = purple sweet } \\
\text { potato flour of } 25 \% \text { : } \\
\text { corn of } 75 \% \\
\text { P3 = purple sweet } \\
\text { potato flour of } 50 \% \text { : } \\
\text { corn of } 50 \% \\
\text { P4 = purple sweet } \\
\text { potato flour of } 75 \% \text { : } \\
\text { corn of } 25 \%\end{array}$ \\
\hline
\end{tabular}

Figure 7. Results of tortillas chip of color analysis

Figure 7 shows that the color test value of corn tortilla chips with purple sweet potato flour obtained 3 spatial coordinates, namely $\Delta \mathrm{L}$ the difference between light and dark (+ light, -dark), $\Delta \mathrm{a}$ the difference between red and green $(+$ red, -green), $\Delta b$ the difference between yellow and blue $(+$ more yellow, -blue), $\Delta \mathrm{E}$ is the total difference. The color of food products is due to the presence of natural pigments contained in food ingredients. This is in accordance with the opinion of Deman, (1997) that the anthocyanin pigments contained in purple sweet potato flour have a major contribution to the formation of the purple color.

Based on the analysis of variance, it shows that the values of $\Delta \mathrm{L}, \Delta \mathrm{E}, \Delta \mathrm{A}$ and $\Delta \mathrm{B}$ of different treatment combinations were not significantly different to the resulting tortilla color values. Based on the values of $\Delta \mathrm{L}-1.40,-4.27,-10.93$ it explains that $\Delta \mathrm{L}$ has a darker color. Based on the value of nilaiA $6.73,11.33,13.60$, it explains that the color is redder, the values of $\Delta B$ 4.7, 28.30, 29.80 explain that this treatment is more yellow. For $\Delta \mathrm{E}$ data in this treatment, it has a value of $15.47,30.87,34.69$ which is not significantly different. This analysis of variance shows that the difference in tortilla treatment has no significant effect on the color obtained, so there is no need for further LSD test. The uniqueness of purple sweet potato flour is the diverse color of the product and follows the tuber meat as the raw material (Widowati S, 2009). 


\subsubsection{Texture}

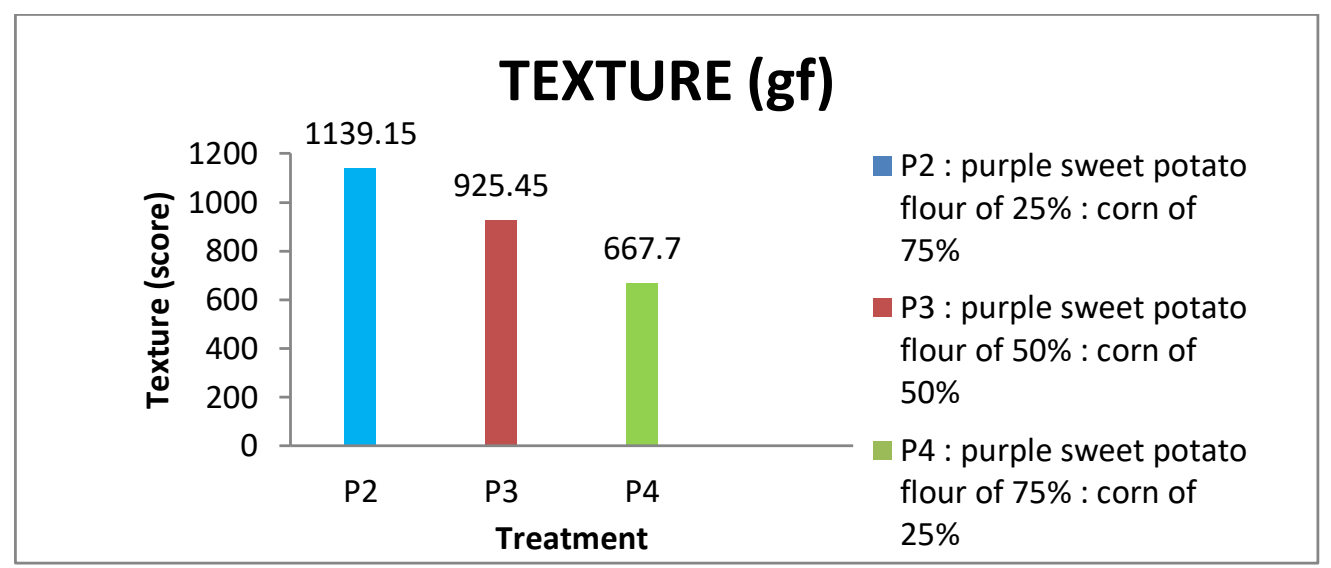

Figure 8. The results of the tortillas chip texture analysis

From the results of Figure 8, the texture analysis in this study was carried out to determine the level of hardness of the tortilla chips produced. Measurements with a texture analyzer, the hardness value is indicated by the maximum force or peak value at the first pressure (Faridah et al 2012).

Based on the results of the tortilla hardness test using a texture analyzer, it can be seen that the higher the proportion of purple sweet potato flour, the lower the hardness value. In P2 treatment, the proportion of purple sweet potato flour of $25 \%$ : $75 \%$ of corn produced the highest hardness, namely 1139.5gf. Meanwhile, the lowest hardness level was in the P4 treatment using the proportion of $75 \%$ purple sweet potato flour and $25 \%$ maize with a hardness value of $667.7 \mathrm{gf}$. This shows that the low hardness value of tortilla chips is caused by the amount of water released from the starch granules which break when drying. This is in accordance with the opinion of Muchtadi et al. (1988) that hardness is influenced by the amount of water bound to the carbohydrate matrix, especially snacks, if the water content is too high it will cause the texture to be less crunchy. The higher the dryness value, the less good the crispy value (Pratiwi, 2003).

Based on the results of the analysis of variance, it shows the texture of the tortillas states that the corn tortillas with purple sweet potato flour are not significantly different so that no further LSD test is carried out. In addition to purple sweet potato flour which affects the hardness level, another binder in the form of meizena flour also affects the hardness level. The higher the concentration of cornstarch that is added, the texture value of the tortilla chips product will increase. The increase in texture value due to the increasing concentration of cornstarch added is thought to be related to the presence of amylose and amylopectin. Amylose levels will increase with increasing starch concentration. Yuliasih et al. (2007). The higher hardness value of tortilla chips can also be caused by the high fiber content in the corn. The higher the fiber, the resulting reduced porosity and greater density, so that the chips / chips become hard (Damayanthi and Listyorini 2006).

Apart from the binder, the increase in the hardness value was caused by external factors, namely the absorption of water when the tortilla chips were stored for a certain period of time so that there was a decrease in crunchiness and an increase in hardness which was higher than food with high amylose (Supriyadi, 2012).

\section{CONCLUSION}

The conclusion from the research results of corn tortilla chips substituted by purple sweet potato flour with three treatments are as follows.

1) The best treatment for tortilla chips substituted by purple sweet potato flour, namely in the organoleptic test, the results for texture, aroma, taste were obtained in the $\mathrm{P} 4$ treatment with the addition of $75 \%$ purple sweet potato flour: $25 \%$ corn, with a texture value of 4.267 , taste 4.75 and aroma 4.56 and for the best color treatment found in the addition of $\mathrm{P} 3$ with the addition of $50 \%$ purple sweet potato flour: $50 \%$ corn with a value of 4.31

2) The best treatment in the chemical analysis test through several parameters in the form of color, moisture content, ash content is the P4 treatment with the addition of $75 \%$ purple sweet potato flour: $25 \%$ corn, with a color value of 10.93, moisture content of 8.94 and ash content of 2.57 . 
3) And for texture analysis test the highest treatment was $\mathrm{P} 2$ treatment with the addition

\section{DAFTAR PUSTAKA}

Andarwulan, N., Kusnandar, F., Herawati, D. 2011. Food analysis. Jakarta: Dian Rakyat.

[AACC] American Association of Cereal Chemists. 1999. AACCI method 66-50.01, pasta and noodle cooking quality -firmness. Di dalam: AACC International Approved Methods of Analysis, Eleventh Edition. St. Paul (USA): AACC International.

[BSN] National Standardization Institute. 1996. Indonesian National Standard, SNI 012974-1996, Dry noodle quality requirements. Jakarta.

Bello A, V. Barreto-Palacios, Segovia-Garcia P, Mir-Bel J, Martinez-Monzo. 2013. Effect of $\mathrm{pH}$ on color and texture of food product. Food Eng 5:158-170.

Damayanthi E, dan Listyorini DI. 2006. Utilization of low-fat bran flour in the manufacture of simulated chips. J. Gizi dan Pangan 1(2):3444

Deman, J. M. 1997. Food chemistry. Dialih bahasakan oleh K. Padmawinata. Penerbit Institut Teknologi Bandung. Bandung.

Dolongseda, W., Ludong M. M., dan Djarkasi S. S. G. 2010. Study of the sensory properties of tortillas substituted with jackfruit seed flour. Ilmu Teknologi Pangan, Fakultas Perta nian UNSRAT, Manado.

Faridah D.N, Kusnandar F, Herawati D, Wulandari N, Kusumaningrum HD, Purnomo EH, dan Indrasti D. 2012. Food analyse. Bogor(ID): Institut Pertanian Bogor.

Koswara S. 2013. Corn processing technology (theory and practice) production : eBook pangan.com

Kusmawati, Aan, H. Ujang, dan E. Evi . 2000. The basics of agricultural product processing. Central Grafika. Jakarta.

Melis M and Barbarossa I.T. 2017. Taste Perceptionof sweet, sour, salty,bitter, and umamiand changes due to L-arginine supplementation, as a function of genetic ability to taste 6-n-Propylthiouracil. Nutrients, 9(541): 1-17.

Mendez-Montealvo , G; Sanchez-Rivera, M. M., Paredes-Lopez, O., dan Bello-Perez, L.A. 2006. Thermal and Rheological Properties of Nixtamalized Maize Starch. Internasional journal of Biological Macromolecus 59-63.

Muchtadi, D., TR., Purwiyatno dan Basuki, A. 1988. Extrusion cooking technology. LSI. Institut Pertanian Bogor. of $25 \%$ purple sweet potato flour: $75 \%$ corn with a value of 1139.15 .

Pratiwi, F. 2003. Kimpul tuber development (Xanthosoma SagittifoliumL. Schot) become chips in order to diversify pastindustri products. [Skripsi]. Bogor. Fakultas Teknologi Pertanian. Institut Pertanian Bogor.

Rodriques, P.B.L Raina, Eb Pantatisco dan M.B Balt. 1998. Quality of raw fruits for physiological processing after harvest. Yogyakarta. Universitas Gaja Mada

Supriyadi, D. 2012. Study of the effect of amylose amylopectin ratio and moisture content on crispness and hardness of fried product models. [Skripsi]. Bogor. Institut Pertanian Bogor.

Stevenson R.J. 2012. The role of attention in flavor perception. Flavour Biomed Cdentral. Depertment of Psychology, Macquarie University, Sydney, NSW, 2109.

Waryoko, 2007. Study of carrageenan extraction from eucheuma cottoni seaweed (Study of immersion and immersion solution types). Jurnal Teknologi Hasil Pertanian

Winarno, F. G., 2004. Chemistry and nutrition. Gramedia Pustaka Utama. Jakarta.

Yuliasih, I., Irawadi, T.T., Sailah, I., Pranamuda, H., Setyowati K. dan Sunarti, T.C. 2007. The effect of the sago starch fractionation process on the characteristics of the amylose fraction. Jurnal Teknologi Industri Pertanian 17(1): 29-36.

Zuraida, N., dan Supriyati, Y. 2011. Sweet potato farming as food. 